\title{
Són les nanopartícules magnètiques una alternativa al tractament d'aigües?
}

\author{
Raul Marta Miranda \\ INS Mercè Rodoreda (L'Hospitalet de Llobregat) \\ raaull.2002@gmail.com \\ Anghelina Salazar Ovando \\ INS Mercè Rodoreda (L'Hospitalet de Llobregat) \\ angied.m0105@gmail.com \\ Yolanda Fernández Caparrós \\ INS Mercè Rodoreda (L'Hospitalet de Llobregat) \\ yfernand@xtec.cat
}

Resum - Es presenta un treball de recerca on s'han explorat les possibilitats que presenta la nanotecnologia en el tractament d'aigües. En concret, s'ha realitzat una depuració d'aigües residuals del clavegueram de l'Hospitalet amb un mètode tradicional floculació-coagulació i utilitzant nanopartícules magnètiques. S'han comparat alguns índexs de qualitat de l'aigua després de la depuració pels dos mètodes.

Paraules clau • treball de recerca, nanotecnologia, nanopartícules magnètiques, depuració d'aigües.

\section{Are magnetic nanoparticles an alternative to water treatment?}

\begin{abstract}
In this investigation we have synthesized two types of nanoparticles to use them in purifying water. Then, we have analysed some parameters of the purified water that define if the water is suitable to return to the environment. The results of the analysis of the purified water have an improvement in the three studied parameters. This investigation has demonstrated that the nanoparticles are an alternative more sustainable than the traditional method of purifying water.
\end{abstract}

Keywords • research project, nanotechnology, magnetical nanoparticles, purifying water 


\section{INTRODUCCIÓ SOBRE L'EXPERIĖNCIA}

En aquest article s'exposa un treball de recerca realitzat amb alumnes de Batxillerat. La recerca es va iniciar al $2 n$ trimestre de $1 r$ de Batxillerat i es va finalitzar al $1 r$ trimestre de $2 n$ de Batxillerat. El treball consta d'una petita part teòrica sobre el problema de l'aigua al món i les solucions que pot aportar la nanotecnología i d'una part pràctica que hem realitzat al laboratori del nostre institut fora de l'horari lectiu.

El treball es va avaluar amb una exposició oral davant d'un tribunal que va tenir en compte el contingut de l'exposició, la correcció del treball escrit i l'avaluació del seguiment realitzat per la tutora. Per tal d'introduir als alumnes al món de la nanotecnologia s'ha fet servir el kit Nanoeduca proporcionat pel centre de recursos pedagògics de l'Hospitalet.

\section{EL PROBLEMA DE L'AIGUA}

L'aigua cobreix el $70 \%$ de la superfície de la Terra, la qual cosa representa al voltant d'uns 1,386 milions de $\mathrm{km}^{3}$. Ara bé, només un 2,5\% d'aquesta aigua és aigua dolça. A més, aquesta aigua dolça es troba en un $70 \%$ en forma de glaceres, neu o gel, un $30 \%$ són aigües subterrànies i menys de l'1\% és aigua disponible pel consum humà $i$ els ecosistemes. És a dir, només $3,465 \times 10^{-4} \mathrm{~km}^{3} \quad 0 \quad 3456000 \mathrm{~m}^{3}$ estan disponibles pel sector agropecuari $(69 \%$ de la despesa total d'aigua), industrial (19\%) o municipal (12\%).

Ara bé, el problema de l'aigua al món no és tant l'escassetat sinó la mala distribució. Alguns dels principals reptes, segons l'Organització de les Nacions Unides (ONU), són la manca d'accés a serveis d'aigua potable i la falta de serveis de sanejament gestionats de manera segura. Hi ha un $80 \%$ de les aigües residuals que retornen a l'ecosistema sense ser tractades o reutilitzades adequadament.

La nanotecnologia presenta diferents propostes per ajudar a solucionar el problema de l'aigua la món. Per exemple, es poden utilitzar nanopartícules magnètiques que poden arrossegar els contaminants de les aigües residuals. Aquestes nanopartícules poden ser recollides i tornades a utilitzar en successius tractaments, la qual cosa suposa un estalvi important en reactius, fent de la depuració amb nanopartícules un tractament molt sostenible.

En aquesta experiència realitzarem una síntesi de nanopartícules magnètiques utilitzant dos mètodes diferents per realitzar a continuació una depuració d'aigües residuals obtingudes del clavegueram de l'Hospitalet. Compararem els resultats que s'obtenen amb els d'una depuració tradicional coagulació-floculació.

\section{SIINTESI DE NANOPARTÍCULES}

\section{Mètode 1 - Síntesi de nanopartícules magnètiques amb Fe (III)}

\section{Reactius}

Dissolucions de $\mathrm{FeCl}_{3} \cdot 6 \mathrm{H}_{2} \mathrm{O} 2 \mathrm{M}, \mathrm{Na}_{2} \mathrm{SO}_{3} 1 \mathrm{M} \mathrm{i}$ $\mathrm{NaOH} 1 \mathrm{M}$

\section{Material}

Vidre de rellotge, espàtula, balança, agitador magnètic, vas de precipitats, matràs aforat de 10 $\mathrm{mL}$ i $100 \mathrm{~mL}$, matràs Erlenmeyer de $100 \mathrm{~mL}$, pipeta graduada de $5 \mathrm{~mL}$, proveta de $100 \mathrm{~mL}$, punter làser i imant de neodimi.

\section{Procediment}

Després de tenir les tres solucions preparades, hem mesclat $3 \mathrm{~mL}$ de $\mathrm{FeCl}_{3} \cdot 6 \mathrm{H}_{2} \mathrm{O}$ i $2 \mathrm{~mL}$ de $\mathrm{Na}_{2} \mathrm{SO}_{3}$ en un vas de precipitats. La solució passa d'un color ataronjat a un de vermell fosc. Posteriorment sobre $10 \mathrm{~mL}$ de la solució de $\mathrm{NaOH}$ hem afegit ràpidament la mescla de color vermell de $\mathrm{FeCl}_{3} .6 \mathrm{H}_{2} \mathrm{O}$ amb $\mathrm{Na}_{2} \mathrm{SO}_{3}$, sota una agitació elevada. S'observa la formació d'un precipitat de color negre. L'agitació ha de continuar durant 20 minuts.

Hem comprovat la presència de nanopartícules amb un làser veient que es produeix l'efecte Tyndall (Fig. 1). Aquest efecte és un fenomen que produeix que les partícules col-loidals en una dissolució siguin visibles en dispersar llum. Hem comprovat el caràcter magnètic arrossegant les nanopartícules amb un imant. Per recollir les nanopartícules hem posat un imant sota el matràs. 
Les nanopartícules es sedimenten al fons i hem decantat el líquid sobrant amb molta cura. El resultat és un líquid molt espès que conté les nanopartícules de color marró.

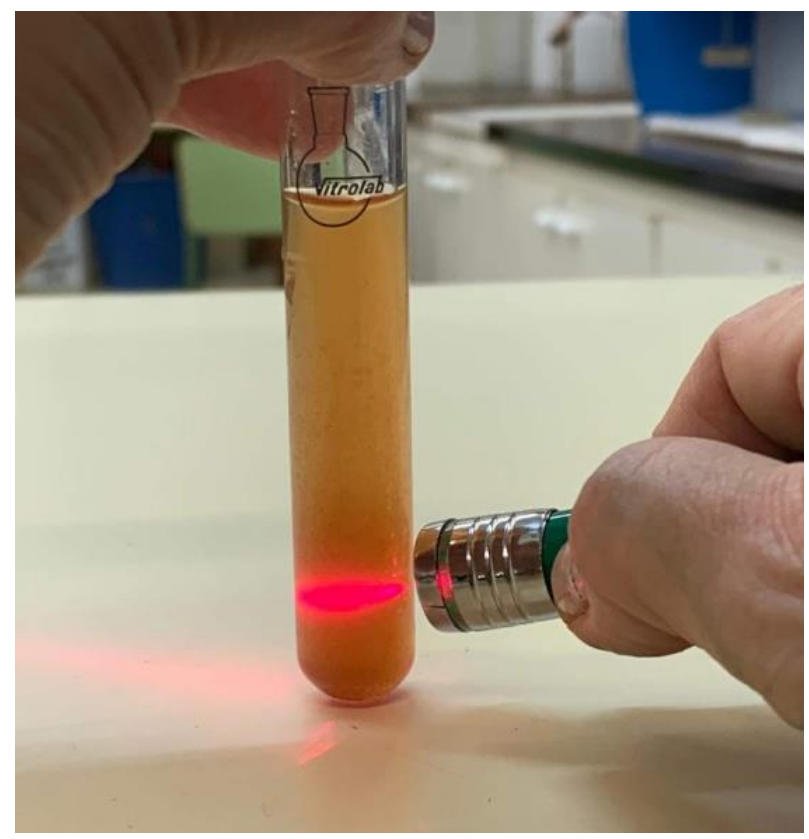

Figura 1: Comprovació de l'efecte Tyndall

Mètode 2 - Síntesi de nanopartícules magnètiques amb Fe (II) i Fe (III)

\section{Reactius}

$\mathrm{FeCl}_{2} \cdot 4 \mathrm{H}_{2} \mathrm{O}$, dissolució concentrada de $\mathrm{FeCl}_{3}$ $(0,325 \mathrm{~g} / \mathrm{mL})$; dissolució $1 \mathrm{M}$ de base $(90 \% \mathrm{NaOH}+$ $10 \%$ hidròxid de tretrametilamoni, TMAOH ) $1 \mathrm{M}$

\section{Material}

Vidre de rellotge, espàtula, balança, agitador magnètic, vas de precipitats, matràs Erlenmeyer de $50 \mathrm{~mL}$, pipeta aforada de $10 \mathrm{~mL}$, comptagotes, punter làser $\mathrm{i}$ imant de neodimi.

\section{Procediment}

Després de tenir les dissolucions preparades, hem mesclat $1 \mathrm{~mL}$ de la dissolucó de $\mathrm{FeCl}_{3}$ i 0,200 $\mathrm{g}$ de $\mathrm{FeCl}_{2} .4 \mathrm{H}_{2} \mathrm{O}$ en un matràs Erlenmeyer de 50 $\mathrm{mL}$ amb $10 \mathrm{~mL}$ d'aigua destil.lada. Posteriorment hem afegit gota a gota els $10 \mathrm{~mL}$ de solució bàsica sota una agitació molt elevada.

Hem comprovat la presència de nanopartícules amb el làser i les hem precipitant al fons del matràs amb un imant, decantant el líquid sobrenedant.

\section{DEPURACIÓ MITJANÇANT UN TRACTAMENT COAGULACIÓ-FLOCULACIÓ}

El tractament tradicional que hem fet servir ha estat el de coagulació/floculació. Hem realitzat el tractament sobre aigües residuals obtingudes del clavegueram d'Hospitalet de Llobregat pels professors del cicle formatiu de grau superior de Química Ambiental de I'INS Mercè Rodoreda. Ells també ens han proporcionat el material per fer aquesta depuració.

Per portar a terme aquest mètode hem seguit els següents passos: primer hem abocat $500 \mathrm{~mL}$ d'aigües residuals a un vas de precipitats. Hem afegit $0,1 \mathrm{~mL}$ de $\mathrm{FeCl}_{3}$ de concentració $100 \mathrm{~g} / \mathrm{L}$ (coagulant) al vas i l'hem deixat a l'agitador a 120 rpm durant 6 minuts. Després d'aquests 6 minuts hem afegit $2 \mathrm{~mL}$ de polietilenglicol (PEG, floculant) $i$ l'hem tornat a deixar a l'agitador a $60 \mathrm{rpm}$ durant 5 minuts (figura 2). Finalment l'hem deixat reposar durant 15 minuts. Hem filtrat l'aigua i hem guardat el filtrat per l'anàlisi posterior.

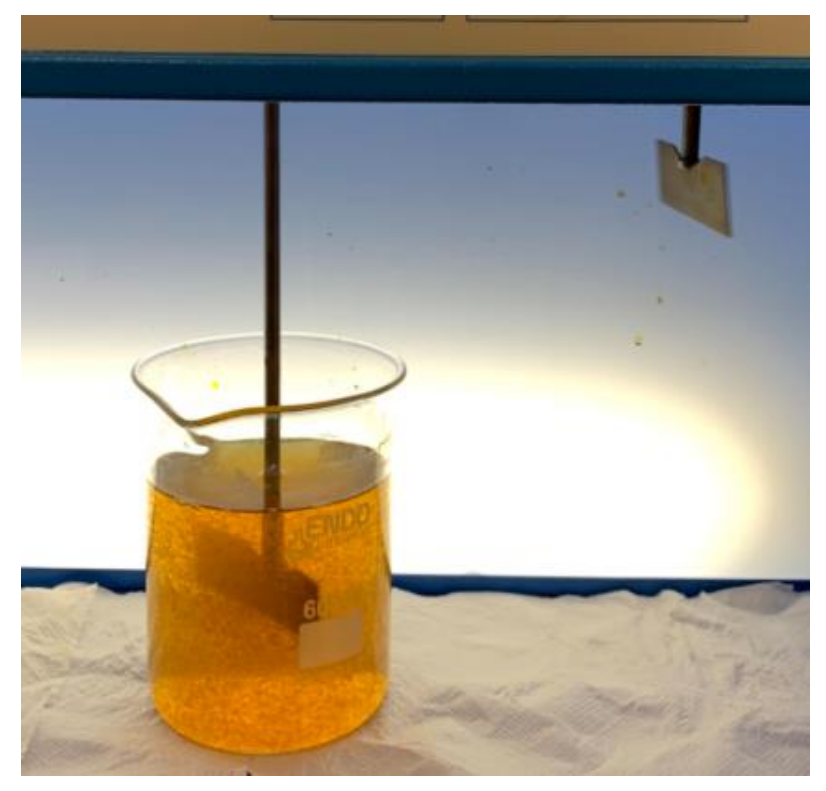

Figura 2: Aigües residuals a l'agitador després d'afegir el coagulant i el floculant. 


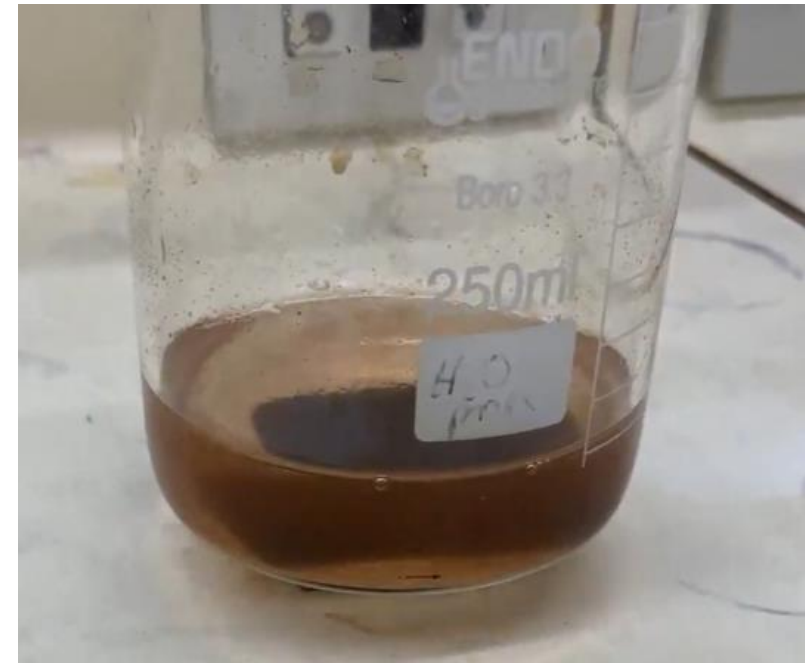

Figura 3: Nanopartícules recollint els contaminants

\section{DEPURACIÓ MITJANÇANT NANOPARTÍCULES MAGNÈTIQUES}

Per portar a terme la depuració amb les nanopartícules magnètiques hem seguit els següents passos: primer en un vas de precipitats hem abocat $20 \mathrm{~mL}$ d'aigua residual $\mathrm{i}$ hem afegit $1 \mathrm{~mL}$ de nanopartícules. Sota el vas hem posat l' imant de neodimi durant 5 minuts perquè les nanopartícules recullin els contaminants $i$ les arrossegui fins al fons del vas (figura 3). Hem decantat l'aigua en un altre vas i l'hem guardat per analitzar.

Aquest procediment l'hem realitzat amb els dos tipus de nanopartícules.

\section{ANÀLISI DE LES AIGÜES DEPURADES}

A partir de l'aigua depurada obtinguda dels tres tractaments anteriors, vam analitzar tres paràmetres, dos físics i un químic: color aparent, $\mathrm{pH}$ i conductivitat.

El color aparent està relacionat amb les substàncies dissoltes i les partícules en suspensió que conté. La mesura del color és important per a conèixer el nivell de matèria orgànica que hi ha en l'aigua perquè la seva presència pot produir un risc de generació de subproductes nocius de la desinfecció de l'aigua. Es mesura en unitats de Platí-Cobalt (Pt-Co). Una aigua de bona qualitat ha de tenir un color aparent màxim de 20 unitats $\mathrm{Pt}$ Co.

$\mathrm{El} \mathrm{pH}$ de l'aigua adequat pel retorn al medi s'ha de trobar entre 6,5 i 8,5.
La conductivitat és una mesura que en dona idea de la quantitat d'ions dissolts a l'aigua. El límit acceptable és, en aquest cas, de $1500 \mu \mathrm{S} / \mathrm{cm}$. Cada mesura s'ha realitzat tres cops i es mostraran les mitjanes.

\section{Color aparent}

Hem mesurat el color amb l'aparell Hanna Checker HI 727. En la taula 1 i la figura 4 es mostren els resultats de l'anàlisi de l'aigua directament extreta del clavegueram, de l'aigua tractada amb el mètode tradicional i de les aigües tractades amb els dos tipus de nanopartícules sintetitzades (mètode $1 \mathrm{i}$ mètode 2 ). $\mathrm{pH}$

Hem mesurat el $\mathrm{pH}$ amb un $\mathrm{pH}$-metre Crison Basic 20. En la taula 2 i la figura 5 es mostren els resultats de l'anàlisi de les diferents mostres d'aigües.

\begin{tabular}{|l|c|}
\hline Aigua clavagueram & $\begin{array}{c}\text { Color aparent } \\
(\mathrm{Pt}-\mathrm{Co})\end{array}$ \\
\hline Tractament tradicional & 435 \\
\hline Nanopartícules 1 & 50 \\
\hline Nanopartícules 2 & 65 \\
\hline
\end{tabular}

Taula 1: Resultats de les mesures de color aparent de l'aigua

Color aparent de l'aigua

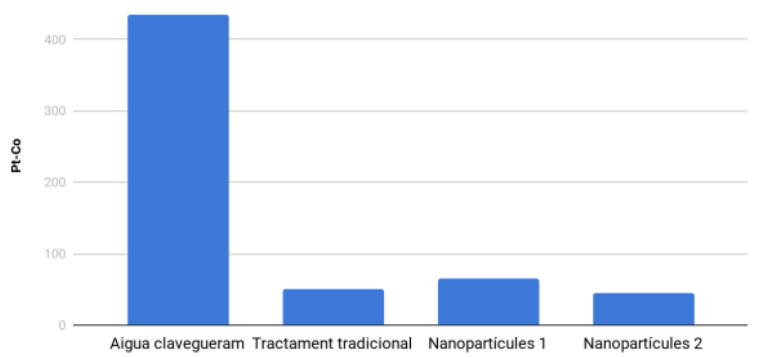

Figura 4: Comparació de les mesures de color aparent

\begin{tabular}{|l|c|}
\hline & $\mathrm{pH}$ \\
\hline Aigua Clavegueram & 8,62 \\
\hline Tractament tradicional & 7,72 \\
\hline Nanopartícules 1 & 10,12 \\
\hline Nanopartícules 2 & 7,5 \\
\hline
\end{tabular}

Taula 2: Resultats de les mesures de $\mathrm{pH}$ de l'aigua 
$\mathrm{pH}$ de l'aigua

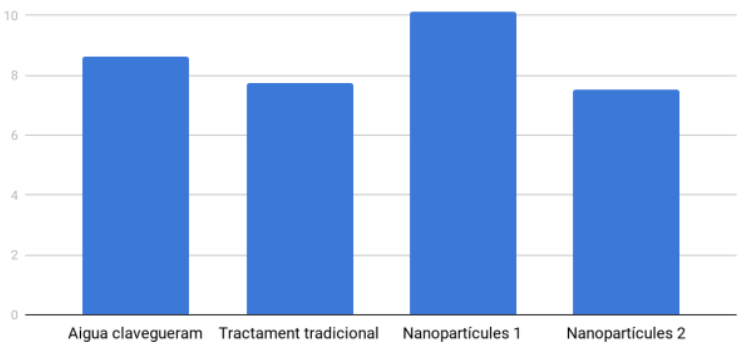

Figura 5: Comparació de les mesures de pH

\section{Conductivitat}

Hem mesurat la conductivitat amb un conductímetre Crison Basic 30. En la taula 3 i la figura 6 es mostren els resultats de l'anàlisi de les quatre mostres d'aigües. Com es pot observar en tots els casos (excepte en el $\mathrm{pH}$ ) qualsevol tractament suposa una millora en els resultats dels paràmetres de qualitat de l'aigua. Pel que fa al color, el tractament tradicional comporta un resultat una mica millor que amb les nanopartícules, però amb aquestes s'obté un resultat prou bo. En el cas del pH s'observa una disminució d'aquest (acostant-se a un valor més proper de 7) tant el tractament tradicional com el realitzat amb les nanopartícules sintetitzades pel mètode 2 .

\begin{tabular}{|l|c|}
\hline & Conductivitat $(\mu \mathrm{S} / \mathrm{cm})$ \\
\hline Aigua clavegueram & 5560 \\
\hline Tractament tradicional & 4700 \\
\hline Nanopartícules 1 & 1040 \\
\hline Nanopartícules 2 & 1020 \\
\hline
\end{tabular}

Taula 3: Resultats de les mesures de conductivitat de l'aigua

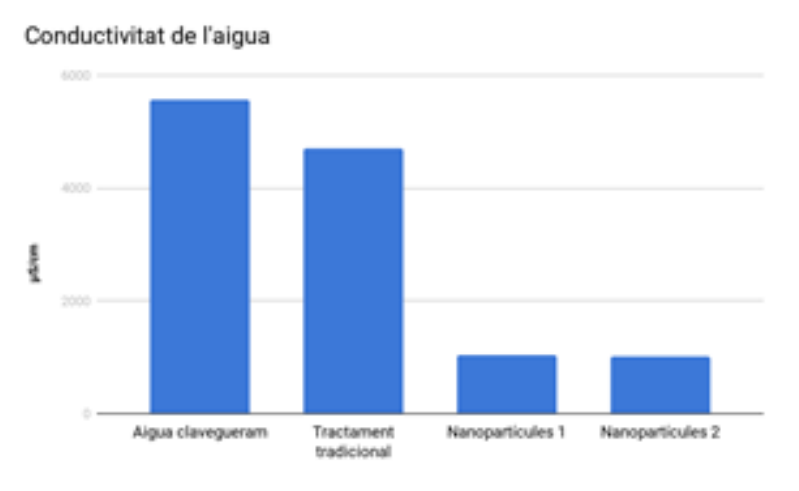

Figura 6: Comparació de les mesures de conductivitat
Amb les nanopartícules del mètode 1 s'ha obtingut una pujada no desitjable del $\mathrm{pH}$. Aquest resultat es pot relacionar amb el mètode de preparació d'aquestes nanopartícules que implica una proporció de base més elevada. Pel que fa a la conductivitat els resultats de la depuració amb nanopartícules són millors que els obtinguts amb el tractament tradicional.

Cal destacar que la depuració amb les nanopartícules sintetitzades pel mètode 2 aconsegueixen disminuir el color, apropar el pH a 7 i disminuir a valors desitjables la conductivitat.

Podem concloure, per tant, que amb el tractament de nanopartícules sintetitzades pel mètode 2 s'obtenen uns bons resultats en la depuració, comparables o inclús millors que els obtinguts amb el tractament tradicional.

\section{CONCLUSIONS}

Amb aquest treball hem aprofundit en el nostre coneixement sobre la problemàtica de l'aigua al món en les possibilitats que ofereix la nanotecnologia en el tractament d'aigües.

Hem comprovat que el tractament d'aigua amb nanopartícules magnètiques és una alternativa més sostenible al tractament tradicional. Amb poca quantitat de producte, i amb la possibilitat de reciclar-lo per repetir el procés, s'obtenen uns paràmetres de qualitat d'aigua prou adequats per retornar l'aigua al medi natural.

Aquest estudi es pot realitzar com a treball de recerca de batxillerat en qualsevol centre educatiu doncs no requereix de material massa sofisticat Precisament, en funció del material que disposi cada centre, es poden ampliar o reduir els paràmetres fisicoquímics o biològics a estudiar.

Realitzant prèviament la síntesi de nanopartícules magnètiques per part del professorat, també tindria aplicació com a pràctica de laboratori a nivell de $3 r$ o $4 \mathrm{t}$ de l'ESO dins la matèries de ciències naturals. 


\section{BIBLIOGRAFIA}

Organització de les Nacions Unides.(2019, 13 d'octubre). Desafíos globales. Agua.

https://www.un.org/es/sections/issuesdepth/water/index.html

Peñate, B. (2019, 9 de novembre) La Nanotecnología para el Tratamiento de las Aguas. Institut tecnològic de Canàries. https://www.iagua.es/blogs/baltasarpenate/nanotecnologia-tratamiento-aguas Casero, E., Briones, C., Serena, P. \& Martín-Gago, J.A. (2014). El nanomundo en tus manos. Crítica. 